\title{
Gene expression pattern and hormonal regulation of Small Proline-Rich Protein 2 family members in the female mouse reproductive system during the estrous cycle and pregnancy*
}

\author{
Yin-fei TAN, Xiao-yang Sun, Fei-xue LI, Shuang TANG, Yun-shang PIAO, \\ Yan-ling WANG**
}

State Key Laboratory of Reproductive Biology, Institute of Zoology, Chinese Academy of Sciences, Beijing 100080, China

(Received 1 February 2006; accepted 7 July 2006)

\begin{abstract}
Small proline-rich proteins (SPRR) are known to construct the cornified cell envelope (CE) in the stratified squamous epithelial cell. Their functions in the simple epithelium such as the uterine epithelium are not clear hitherto. In the present study, the mRNA expression patterns of sprr2 family members in the mouse uterus and vagina during the estrous cycle and pregnancy as well as their regulation by steroids were investigated. Using semi-quantitative RT-PCR, it was revealed that the transcripts of $s p r r 2 b, 2 e$ and $2 g$ genes were up-regulated in the proestrous and estrous uteri, and $s p r r 2 d$ was up-regulated only in the estrous uterus. In the vagina, transcription of $\operatorname{sprr} 2 a, 2 b, 2 d, 2 e$ and $2 k$ genes were up-regulated at the metestrous stage. Northern blot analysis demonstrated that the overall expression of sprr 2 was highly up-regulated in the estrous uterus and the metestrous vagina. During pregnancy, the sprr2 mRNA in the uterus was sharply repressed from day 3 postcoitus on, and began to be induced around labor time. In situ hybridization showed that the sprr2 transcripts were localized in uterine luminal and glandular epithelial cells as well as vaginal stratified epithelial cells. In ovariectomized mice, the expression of $s p r r 2 a, 2 d, 2 e$ and $2 f$ genes in the uterus were induced by estrogen, and the effect of estrogen on $s p r r 2 d$ and $2 e$ expression could be partly abolished by progesterone. The data indicate that the sprr2 genes have unique regulation patterns in different reproductive tissues under different physiological conditions, and the encoded proteins might play diverse functions in the female reproductive system.
\end{abstract}

small proline-rich protein / uterus / estrous cycle / pregnancy / stress

\section{INTRODUCTION}

The uterus is a dynamic organ that shows specific morphological and functional change during the estrous cycle as

\footnotetext{
* This work was supported by the NSFC Project Grant (30370542) and the funds of the CAS knowledge Innovation Program (KSCX3-IOZ07 and KSCX-2-SW-201).

** Corresponding author: wangyl@ioz.ac.cn
}

well as the processes of embryonic implantation and placentation. However, the molecular mechanism underlying uterine multifunction remains largely unclear hitherto. Previously, we mapped the gene expression profile in the mouse uterus during the estrous cycle by using microarray technology. More than one hundred differentially expressed genes were found, among which the most up-regulated gene at estrus 
vs. diestrus was the gene encoding family 2 of small proline-rich proteins (SPRR2) [1].

The knowledge about the functions of SPRR members was confined to the squamous epithelial cells. SPRR proteins serve as precursors to construct the cornified cell envelope (CE) in the stratified squamous epithelium, which functions as a unique protective shield against environmental insults such as trauma, wear-and-tear and loss of body water [2]. The CE complex also entails other proteins including involucrin, loricrin, cystatinA and filaggrin [3], and transglutaminase (GTase) was thought to be the primary enzyme that added SPRR2 proteins to the CE complex by crosslinking the heads and tails of SPRR2 with the other structural proteins [4]. Data from Turksen and Troy showed that mice with defective CE caused by overexpressing claudin6 exhibited neonatal death due to unquenchable infection, outflow of water and temperature instability [5]. Similarly, mice with the GTase 1 gene knockout died as neonates, lacking the normal insoluble cornified envelope and having impaired barrier function [6]. However, the knockout of genes encoding some $\mathrm{CE}$ proteins such as involucrin, loricrin and envoplakin did not abolish CE formation and only slightly affected CE function, suggesting the existence of some compensatory mechanisms preventing a more severe skin phenotype [7-9].

Up to now, four families of sprr genes have been identified in mice. These are families of sprrl (two members), sprr2 (eleven members), sprr3 (one member) and sprr4 (one member) $[10,11]$. The eleven members of the sprr2 gene family have been named from $a$ to $k$ based on their linear arrangement on the gene locus. The high homology in the coding regions of sprr2 genes indicated that their gene locus was expanded through a common ancestor gene by multiple intra- and inter-genic duplications $[12,13]$. The different regulatory elements on their promoters indicated that the divergent regulation of $s p r r 2$ members allowed the fine-tuning of the CE barrier for the optimal protection of the organism [10]. Interestingly, sprr mRNA and the corresponding proteins were recently found in the uterine epithelium and ovary where only simple epithelium or simple epithelium-like cells exist. Specifically, the human ovary expresses sprr1, 2 and 3, whereas human and mouse uteri express sprr 2 but not sprr 1 and $3[13,14]$. Therefore, the question of the novel role of sprr 2 proteins in the reproductive process has arisen. It is thought that these uterine CE precursors might reflect a predisposition of this epithelium to undergo squamoid differentiation under certain conditions [15]. However, there is little further report on their regulation and function in the reproductive tissues so far.

In the present study, semi-quantitative RT-PCR and northern blot analysis were used to investigate the expression patterns of sprr2 in the mouse uterus, ovary and vagina during different stages of the estrous cycle and pregnancy. The mRNA localization of the sprr2 gene in the uterus and vagina was demonstrated by in situ hybridization. Furthermore, the regulation of sprr 2 expression by steroid hormones was studied in the ovariectomized mice. Based on these data, the possible protective role of sprr 2 products in the female reproductive system was suggested.

\section{MATERIALS AND METHODS}

\subsection{Animal treatment and tissue collection}

Mature virgin female CD- 1 mice at the age of six weeks (about $26 \mathrm{~g}$ ) were obtained from the Laboratory Animal Center, National Research Institute for Family Planning (Beijing, China). The mice were housed with the lights on for $12 \mathrm{~h}$ daily and fed ad libitum. Vaginal smears were 
examined daily to classify the phases of the estrous cycle [16]. Mice with at least two consecutive 4-day cycles were chosen for tissue collection and mating. The uteri, vaginas and ovaries at the proestrous, estrous, metestrous and diestrous stages were harvested, respectively. For the mating mice, the day when a virginal plug appeared was considered as the first day of pregnancy. For the pregnant ones, the uteri and placentas (if have) were collected at $1300-1400 \mathrm{~h}$ on gestational days $1,2,3,4,13,20$ and one day after delivery, respectively. On gestational day 4 when implantation just occurred, the uteri were collected as the implantation sites and the inter-implantation sites after venous injection of Evans blue dye (1\% in saline) at 2200-2300 h [17]. Another forty mice were subjected to ovariectomies, and two weeks later, the mice were randomly divided into four groups. They received subcutaneous injection of $17-\beta$ estradiol $\left(\mathrm{E}_{2}\right.$, $200 \mathrm{ng} / \mathrm{mice} /$ day, Group E), progesterone (P, $1 \mathrm{mg} / \mathrm{mice} /$ day, Group P), a combination of $E_{2}$ and $P$ (Group EP), and vehicle (peanut oil, $0.1 \mathrm{~mL} /$ mice/day, Group C) for 3 days, respectively [18]. The animals were sacrificed $24 \mathrm{~h}$ after the last hormone injection and then the uteri and vaginas were harvested. All the tissues were flash frozen in liquid nitrogen and then stored at $-80{ }^{\circ} \mathrm{C}$.

\subsection{RNA isolation and semi-quantitative RT-PCR}

Total RNA were isolated using TRIzol reagent (Invitrogen, CA, USA) according to the manufacturer's instructions. RNA were subjected to digestion with DNase I, and then extracted with phenol:chloroform:isopropyl alcohol (25: 24:1) (Sigma) and concentrated by ethanol precipitation. One microgram of total RNA was reverse transcribed in a $20 \mu \mathrm{L}$ reaction mixture with oligo(d)T primers
(Promega, Madison, USA) and SuperScript II reverse transcriptase as specified by the manufacturer (Invitrogen, CA). One microliter aliquot from the reverse transcription was subjected to PCR amplification with specific sets of primers (SBS Genetech, Beijing, China) listed in Table I. The cycling numbers of the PCR reactions ranged from 20 to 35 according to the abundance of various transcripts, to ensure the amplifications were performed within the exponential phase (Tab. II). All the PCR products were then subcloned into the pGEM-T easy vector (Promega, Madison) and verified by sequencing.

\subsection{Northern blot analysis}

Total RNA $(25 \mu \mathrm{g})$ and the $3 \mu \mathrm{L}$ RNA marker were subjected to electrophoresis on $1 \%$ formaldehyde agarose gels and then vacuum transferred to Hybond ${ }^{+}$nylon membranes (Pharmacia, NJ). Wet membranes were crosslinked by an ultraviolet crosslinker for $8 \mathrm{~s}$. The pGEM-T easy vectors containing the cDNA fragments of sprr $2 a, 2 f$ or gapdh genes were used to generate $\left[\alpha-{ }^{32} \mathrm{P}\right] \mathrm{dCTP}$ labeled probes (Yahui, Beijing, China) by the Primea-gene system (Promega, Madison). The membranes were pre-hybridized for $4 \mathrm{~h}$ at $65{ }^{\circ} \mathrm{C}$ in pre-hybridization buffer $(0.2 \mathrm{M}$ sodium phosphate $\mathrm{pH} 7.4,0.1 \mathrm{mM}$ EDTA, $7 \%$ [w/v] SDS, $1 \%$ [w/v] BSA, and 15\% $[\mathrm{v} / \mathrm{v}]$ formamide), and further hybridized overnight at $65^{\circ} \mathrm{C}$ with the sprr 2 or gapdh probe, respectively. After hybridization, the membranes were washed and then exposed to Fuji film (Fuji Photo Film Co., Tokyo, Japan) at $-80{ }^{\circ} \mathrm{C}$ for the desired time. The signals were quantified with the densitometric scanner (Amersham Biosciences, Buckinghamshire, England) and normalized with the density of the gapdh signal. 
Table I. Primers used in RT-PCR.

\begin{tabular}{|c|c|c|c|}
\hline Gene symbol & Primer sequences & $\begin{array}{l}\text { Product } \\
\text { size (bp) }\end{array}$ & $\begin{array}{l}\text { GeneBank } \\
\text { accession No. }\end{array}$ \\
\hline sprr2a & Forward: 5'- AAGTAAAAGAGGCAATCCAGG & 579 & AJ005559 \\
\hline (as Northern blot probe) & Reverse: 5'- CATCATAGGCACATGGAGG & & \\
\hline $\operatorname{sprr} 2 a$ & F: 5'- CCTTGTCGTCCTGTCATGTGC & 167 & AJ005559 \\
\hline $\operatorname{sprr} 2 b$ & $\begin{array}{l}\text { R: 5'- CCTTCACCTGTTGGGTGGTCA } \\
\text { F: 5'- CTGAGACTCAAGTACGATGTCTTACTACC } \\
\text { R: 5'- CTGGGAAACCCTCATTTATTCTTGGGTGGA }\end{array}$ & 323 & AJ005560 \\
\hline sprr2d & $\begin{array}{l}\text { F: 5'- ACCCGATCCTGAGAATCCAGCACT } \\
\text { R: 5'- TTTGTCCTGATGACTGCTGAAGAC }\end{array}$ & 307 & AJ005562 \\
\hline sprr2e & $\begin{array}{l}\text { F: 5'- ATCCTGAGAATTCAGCACTATG } \\
\text { R: 5'- CTTGTCCCGATGACTGCTGAATC }\end{array}$ & 275 & AJ005563 \\
\hline $\operatorname{spr} 2 f$ & $\begin{array}{l}\text { F: 5'- TCATTCCAGCAGAAATGC } \\
\text { R: 5'- CTGAACAATGGAACAAGACC }\end{array}$ & 308 & AJ005564 \\
\hline $\operatorname{spr} 2 g$ & $\begin{array}{l}\text { F: 5'- ATCCTGAGACTTCAGAAAGATG } \\
\text { R: 5'- TTGTTCTGAAGATTGCTGCCATGC }\end{array}$ & 273 & AJ005565 \\
\hline $\operatorname{sprr} 2 h$ & $\begin{array}{l}\text { F: 5'- GGAGAACCTGAACCTAAGACTTC } \\
\text { R: 5'- GGGAAGATGGAGGTGTTGCTATGG }\end{array}$ & 436 & AJ005566 \\
\hline sprr2i & $\begin{array}{l}\text { F: 5'- ATCCTGAGATCTCAGCACTATG } \\
\text { R: 5'- TCTTGGTCTCGATGAATGCTGAGGCAT }\end{array}$ & 277 & AJ005567 \\
\hline $\operatorname{sprr} 2 j$ & $\begin{array}{l}\text { F: 5'- ATCCTGAGATTTCAGCACTATG } \\
\text { R: 5'- GGGCTTATGTAAGATGGATTCTG }\end{array}$ & 322 & AJ005568 \\
\hline $\operatorname{sprr} 2 k$ & $\begin{array}{l}\text { F: 5'- AGATCCTGAGACATCATAATG } \\
\text { R: 5'- GGTCTTGATGATTGCTAAAG }\end{array}$ & 249 & AJ005569 \\
\hline GTase3 & $\begin{array}{l}\text { F: 5'- TCACGTCTGGAATGAAGG } \\
\text { R: 5'- GGGGAAAATCTCAAATCG }\end{array}$ & 1000 & L10385 \\
\hline involulcrin & $\begin{array}{l}\text { F: 5'- CACACTGCCAGTGACTGTTCC } \\
\text { R: 5'- TCTGATCCCCTGCCATATCC }\end{array}$ & 902 & L28819 \\
\hline gapdh & $\begin{array}{l}\text { F: 5'-ACGACCCCTTCATTGACC } \\
\text { R: 5'-TCAGATGCCTGCTTCACC }\end{array}$ & 700 & M32599 \\
\hline
\end{tabular}

Table II. Cycling number used in amplifying specific cDNA in the uterus, vagina and ovary by semi-quantitative RT-PCR.

\begin{tabular}{lccccc}
\hline & Mice with normal estrous cycle & & \multicolumn{2}{c}{ Ovariectomized mice } \\
\hline & uterus & vagina & ovary & uterus & vagina \\
\hline sprr2a & 23 & 25 & 35 & 25 & 25 \\
sprr2b & 25 & 25 & 35 & 25 & 28 \\
sprr2d & 25 & 25 & 35 & 25 & 25 \\
sprr2e & 25 & 25 & 35 & 25 & 25 \\
sprr2f & 23 & 25 & 35 & 23 & 23 \\
sprr2g & 28 & 25 & 35 & 35 & 25 \\
sprr2h & 28 & 25 & 35 & 35 & 25 \\
sprr $2 i$ & 35 & 35 & 35 & 35 & 35 \\
sprr $2 j$ & 35 & 35 & 35 & 35 & 35 \\
sprr $2 k$ & 35 & 35 & 35 & 35 & 35 \\
GTase3 & 35 & 35 & 30 & 35 & 25 \\
involucrin & 30 & 30 & 35 & 35 & 25 \\
gapdh & 20 & 20 & 20 & 20 & 20 \\
\hline
\end{tabular}




\subsection{In situ hybridization}

Tissue sectioning, DIG-labeling and in situ hybridization were performed as previously described [19]. In brief, the uterine tissues were washed twice with phosphatebuffered saline (PBS) buffer and fixed in $4 \%$ paraformaldehyde (PFA) at $4{ }^{\circ} \mathrm{C}$ overnight. The fixed tissues were then gradually dehydrated in ethanol and embedded in paraffin. The sections were collected on Super Frost+ glass slides (Menzel-Gläser, Germany). To generate DIG-labeled RNA probes, the pGEM-T easy vector containing the cDNA fragment of $\operatorname{sprr} 2 f$ gene was linearized and used as the template to synthesize DIG-labeled sense or anti-sense RNA probes using the DIG-Labeling System (Roche, IN). The probes were stored at $-80^{\circ} \mathrm{C}$ until use. For in situ hybridization, paraffin sections were routinely deparaffinized and rehydrated. The slides were denatured subsequently at $70{ }^{\circ} \mathrm{C}$ in $2 \times \mathrm{SSC}$ for $15 \mathrm{~min}$ and digested with $4 \mu \mathrm{g} . \mathrm{mL}^{-1}$ of proteinase $\mathrm{K}$ (Invitrogen) for another $15 \mathrm{~min}$. Post-fixation was performed in 4\% PFA at room temperature for $10 \mathrm{~min}$, followed by acetylation in triethanolamine buffer containing $0.5 \%$ acetic anhydride for $10 \mathrm{~min}$ and subsequent equilibration in $5 \times \mathrm{SSC}$ for $15 \mathrm{~min}$. The slides were pre-hybridized for $4 \mathrm{~h}$ at $58{ }^{\circ} \mathrm{C}$ in pre-hybridization buffer $(50 \%$ formamide, $20 \mathrm{mM}$ Tris-HCl, $50 \mathrm{mM}$ EDTA, tRNA Coli $0.5 \mathrm{mg} \cdot \mathrm{mL}^{-1}$, DTT $100 \mathrm{mM}$ ) and further hybridized for $18 \mathrm{~h}$ at $58{ }^{\circ} \mathrm{C}$ in fresh hybridization buffer containing 1 ng. $\mu \mathrm{L}^{-1}$ anti-sense DIG-RNA probes. After washing with $2 \times$ SSC and $0.1 \times$ SSC at $65{ }^{\circ} \mathrm{C}$ for $1 \mathrm{~h}$, the slides were submitted to $50 \mu \mathrm{g} . \mathrm{mL}^{-1}$ RNaseA digestion at $37{ }^{\circ} \mathrm{C}$ for $15 \mathrm{~min}$. Then the slides were blocked with $0.5 \%$ blocking reagent buffer (Bochringer Mannheim, Germany) and incubated with alkaline phosphatase-coupled anti-digoxigenin antibody for $2 \mathrm{~h}$. Color development was performed in buffer II (100 mM Tris-HCl, 100 mM NaCl, 50 mM
$\mathrm{MgCl}_{2}, \mathrm{pH}$ 9.5) containing 4.5 $\mu \mathrm{L}$ NBT and 3.5 $\mu \mathrm{L}$ BCIP (Bochringer Mannheim). The slides were mounted in Clearmount (Zymed, San Francisco, USA) without counterstaining. The negative control was performed with the sense RNA probe replacing the corresponding antisense probe in hybridization buffer.

\subsection{Statistics}

The RT-PCR, northern blot analysis and in situ hybridization were performed for at least three times with three independent pools of RNA samples, each pool was derived from specific tissues of at least ten mice. For RT-PCR and northern blot analysis, the relative amount of target mRNA was measured by comparing its densitometry value with that of gapdh. The data was expressed as mean \pm SD according to the results from the three independent experiments. A comparison of the relative densities between groups was performed by One way ANOVA and $P<0.05$ was considered as significant.

\section{RESULTS}

\subsection{Expression pattern of sprr2 members in the uterus during the estrous cycle}

Expression of eleven sprr2 members $(2 a, 2 b$ and $2 d$ to $2 k$ ) in cycling uteri was analyzed by semi-quantitative RT-PCR. Expression of $\operatorname{spr} 2 c$ was not detected because it was identified as a pseudogene [13]. Each PCR was performed with the optimal cycling numbers to ensure that the amplification was within the exponential phase (Tab. II). In the uterus, the transcription of $s p r r 2 a, 2 b, 2 e$ and $2 g$ was up-regulated at the proestrous and estrous stages, and $2 d$ only at the estrous stage. However, mRNA of $s p r r 2 h, 2 i, 2 j$ 


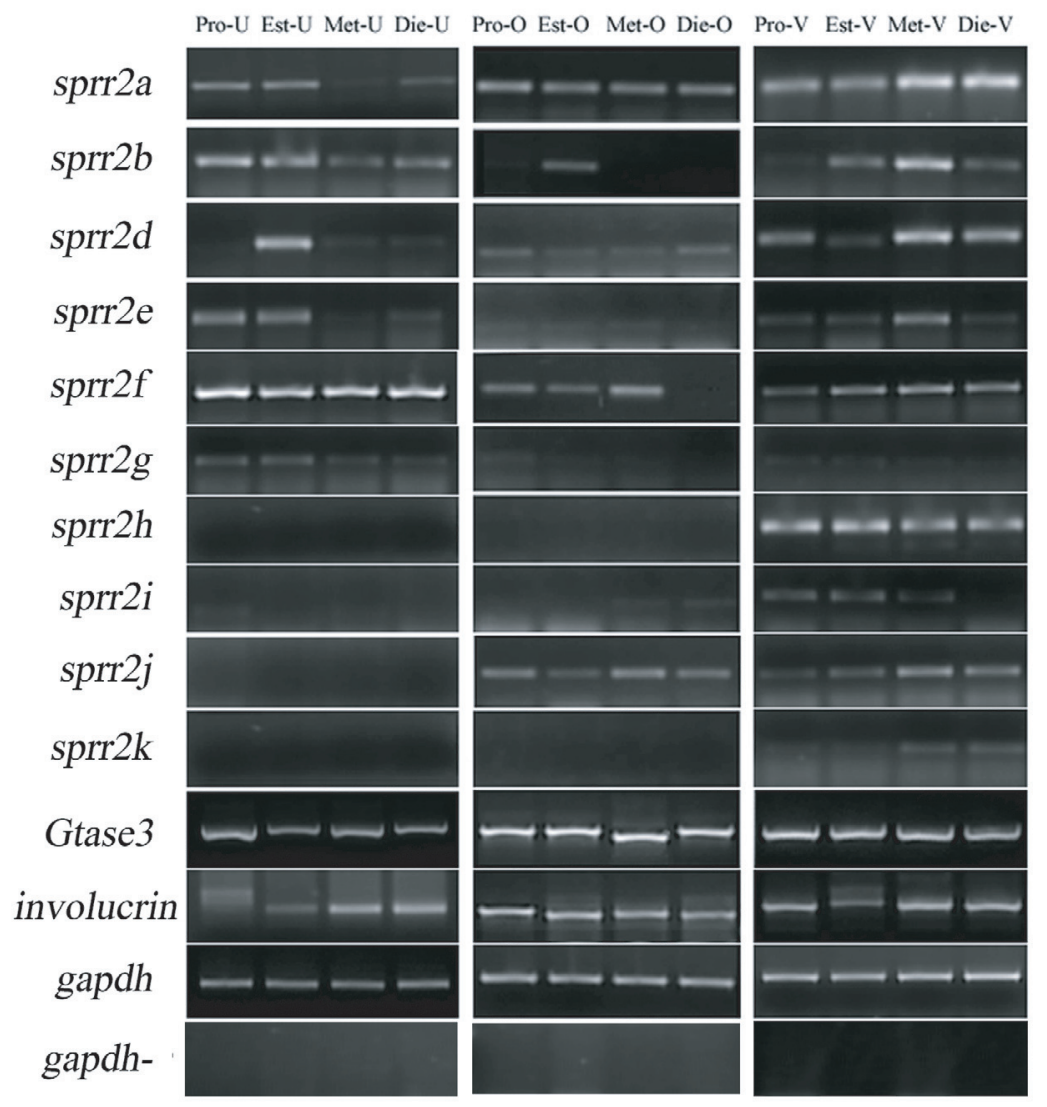

Figure 1. Semi-quantitative RT-PCR of various sprr2 members, GTase 3 and involucrin in the mouse uterus $(\mathrm{U})$, ovary $(\mathrm{O})$ and vagina $(\mathrm{V})$ at the proestrous (Pro), estrous (Est), metestrous (Met) and diestrous (Die) stages. Amplification of the gapdh gene was set to monitor the starting quantity of the template cDNA. A negative control was set by amplifying the gapdh gene with total RNA without reverse transcription (gapdh-).

and $2 k$ were hardly detectable in the uterus at any stage. The expression of involucrin slightly increased at the metestrous and diestrous stages, while GTase3 remained stable throughout the estrous cycle (Fig. 1).

The eleven sprr2 transcripts are similar in sizes and highly homologous [13]. Therefore, it is unfeasible to design distinct probes for detecting each member by northern blot analysis. The cDNA probes used here were designed according to the cDNA sequences of sprr2a and sprr2f genes with the length of $579 \mathrm{bp}$ and
$308 \mathrm{bp}$, respectively. Hybridization with these two probes gave the same signal at about $1.9 \mathrm{~kb}$, which represented the overall transcripts of different sprr 2 members (Data generated by the sprr2f probe was not shown). Surprisingly, the amount of sprr2 mRNA in the uterus was significantly higher than that in the footpad which was thought to be the typical tissue with CE structure. Statistical analysis showed that the overall expression of $s p r r 2 \mathrm{mRNA}$ reached a much higher level in the proestrous and estrous uteri, which was more 


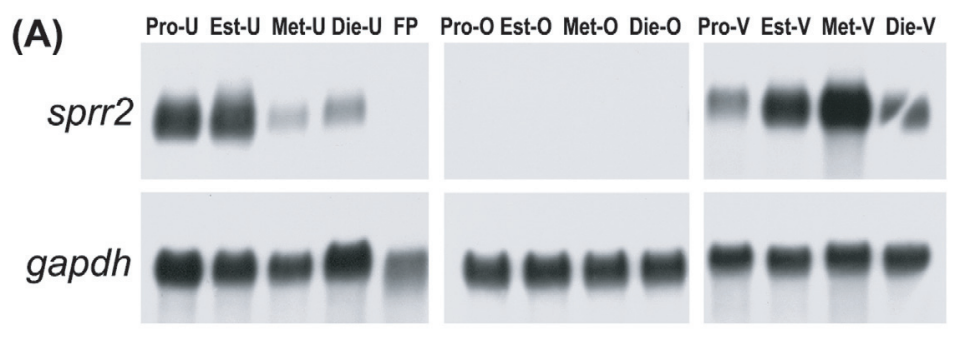

(B)
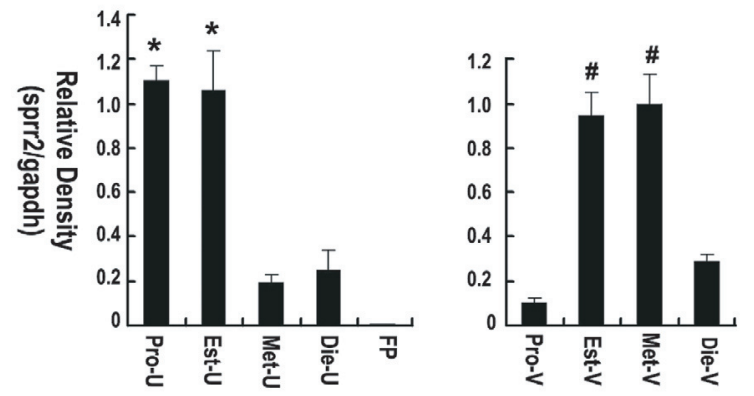

Figure 2. Northern blot analysis revealing the overall expression of sprr2 in the mouse uterus (U), ovary (O) and vagina (V) during the estrous cycle. The 579 bp PCR product from sprr2a was used as a probe here and in FIG4 and FIG6. Pro, proestrus; Est, estrus; Met, metestrust; Die, diestrus. A. The autoradiogram of a representing northern blotting. B. The densitometric analysis of the autoradiogram. The relative amount of sprr2 was normalized by value of gapdh, and statistical analysis was performed by ANOVA on the data from three independent experiments. * Compared with Die-U, $P<0.05$; \# compared with Die-V, $P<0.05$.

than 4-fold of that in the metestrous or diestrous uteri (Fig. 2).

In situ hybridization was performed to reveal the detailed localization of sprr2 mRNA. In the uterus, sprr2 transcripts were mainly localized in the luminal and glandular epithelial cells, and the signal was stronger in the proestrus and estrus than that in the metestrus and diestrus (Fig. 3A), which was inconsistent with the result of the northern blot analysis.

\subsection{Expression pattern of sprr2 members in the vagina during the estrous cycle}

In the vagina, the expression pattern of $s p r r 2$ mRNA was quite different from that in the uterus. By RT-PCR, the mRNA of all sprr2 members was detectable except for $\operatorname{sprr} 2 g$, although the levels of $s p r r 2 i$, $2 j$ and $2 k$ were relatively low. The expression of $\operatorname{sprr} 2 a, 2 b, 2 d, 2 e, 2 j$ and $2 K$ was up-regulated at the metestrus, whereas $2 i$ was induced at proestrus and estrus. The expression of involucrin was repressed at the estrous stage, while GTase 3 exhibited stable expression during the estrous cycle (Fig. 1). Using northern blot analysis, it was shown that the sprr 2 mRNA level started to increase at estrus and reached a plateau at metestrus, then decreased at diestrus and proestrus. The level of sprr 2 mRNA in the metestrous vagina was more than 5-fold of that in diestrus (Fig. 2).

In situ hybridization revealed that the sprr2 transcript was distributed in the 

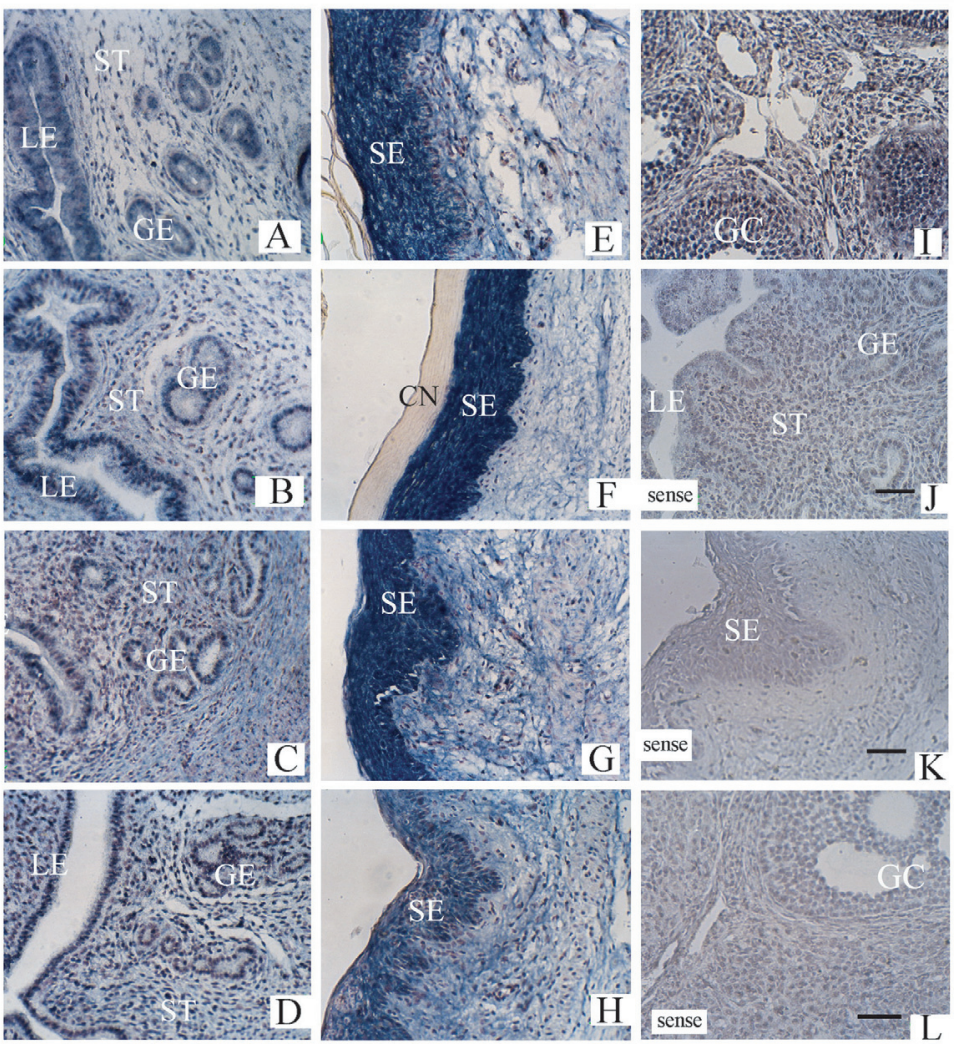

Figure 3. In situ hybridization revealing the localization of sprr $2 \mathrm{mRNA}$ in the mouse uterus, vagina and ovary at the proestrous (Pro), estrous (Est), metestrous (Met) and diestrous (Die) stages. A-D. In the uterus, sprr2 transcripts were mainly localized in the luminal (LE) and glandular (GE) epithelial cells. ST, stromal cells. E-H. In the vagina, sprr2 transcripts were localized in the stratified epithelial cells (SE). CN, keratinized layer. I. In the ovary, the granulosa cells (GC) possessed a weak positive signal for $s p r r 2$ transcripts. Sense hybridization with the sense RNA probes in the estrous uterus ( $\mathbf{J})$, vagina $(\mathbf{K})$ and ovary $(\mathbf{L})$ were set as negative controls. The scale bar represents $40 \mu \mathrm{m}$.

stratified epithelial cells, and the signal intensity was higher at the estrous and metestrous stages than at the diestrous and proestrous stages (Fig. 3B), which was similar with the data of Northern blot analysis.

\subsection{Expression pattern of sprr2 members in the ovary during the estrous cycle}

In the ovary, RT-PCR demonstrated that $\operatorname{sprr} 2 a, 2 b, 2 d, 2 f, 2 j$, involucrin and
GTase3 were expressed at low levels: the expression of sprr $2 a, 2 d, 2 j$, involucrin and GTase 3 appeared stable during the estrous cycle, $2 b$ increased at estrus, and $2 f$ decreased at diestrus and metestrus (Fig. 1). The low expression of $s p r r 2$ genes in the ovary was also proven by northern blot analysis, in which no signal was found after exposing to X-film for 1 day (Fig. 2), and a very weak signal appeared after 7-day exposure to the X-film (data not shown). 


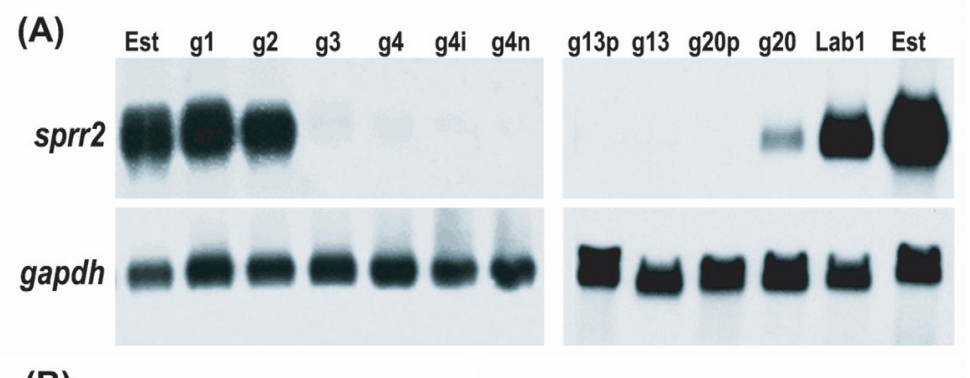

(B)

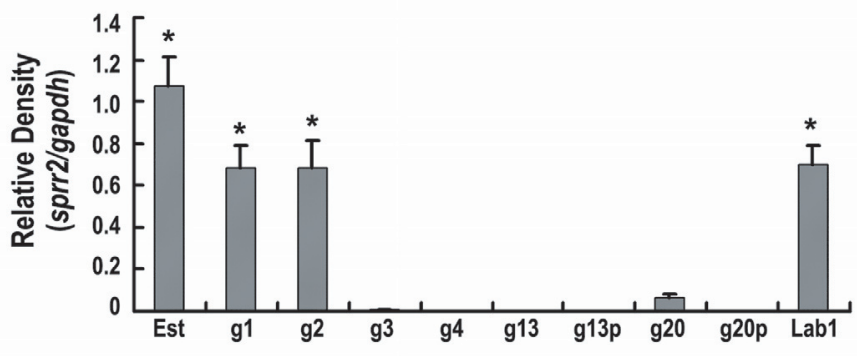

Figure 4. The overall expression of $s p r r 2$ mRNA in the mouse uterus and placenta during normal pregnancy as revealed by northern blot analysis. A. Autoradiogram of a representing northern blot. B. Densitometric analysis of the autoradiograms. The relative amount of $s p r r 2$ was normalized by a value of gapdh, and statistical analysis was performed by ANOVA according to the data from three independent experiments. g1, g2, g3, g4, g13 and g20 represent gestational days 1, 2, 3, 4, 13 and 20, respectively. Lab1, the first day after labor; i, implantation site; n, non-implantation site; $\mathrm{p}$, placenta; * Compared with the amount in g20, $P<0.05$.

In situ hybridization showed that only the granulosa cells exhibited very weak signals for sprr2 hybridization (Fig. 3C).

\subsection{The expression pattern of sprr2 mRNA in the mouse uterus and placenta during pregnancy}

The expression of sprr 2 mRNA in the mouse uterus and placenta from gestational day 1 till the first day after labor was analyzed by northern blot analysis. In the uterus, a high level of sprr 2 mRNA was observed on the 1st and 2nd day of pregnancy. The overall transcription decreased greatly from the 3rd day on, and remained hardly detectable until the 20th day of pregnancy when the expression was slightly induced again. On the first day after labor, sprr2 expression retained to the relatively high level which was almost the same as that on the first day of gestation (Fig. 4).

In the placenta, the sprr2 transcripts were scarcely detectable during the whole pregnancy period (Fig. 4).

\subsection{Regulation of sprr2 expression by steroid hormones}

The ovariectomized mice were used to determine the effect of steroid hormones on sprr2 expression in the uteri and vaginas.

In the uteri, RT-PCR revealed very weak basal expressions of $s p r r 2 b, 2 f$ and involucrin genes. $17 \beta$-estradiol (E2) could 


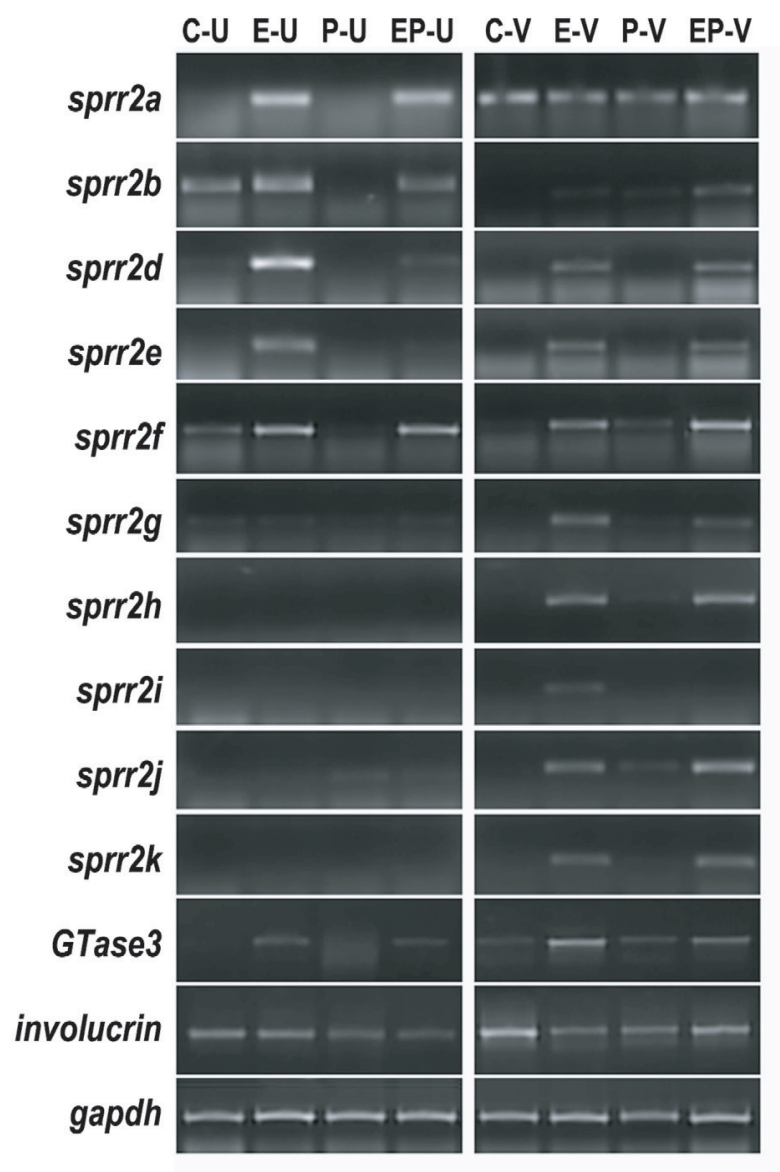

Figure 5. Semi-quantitative RT-PCR demonstrating the regulation of sprr2, GTase 3 and involucrin expression by steroid hormones in the uterus and vagina of the ovariectomized mouse. The ovariectomized mice were treated with vehicle (C), estradiol (E), progesterone (P) or the combination of estradiol and progesterone (EP) for 3 days, and RNA was extracted from the uterus $(\mathrm{U})$ and vagina (V). evidently induce the expression of sprr $2 a$, $2 b, 2 d, 2 e, 2 f$ and GTase 3 genes, while progesterone inhibited the basal expression of $s p r r 2 b$ as well as the E2-induced expression of $2 b, 2 d$ and $2 e$ genes. Expression of the involucrin gene was not influenced by either E2 or progesterone (Fig. 5). By northern blot analysis, it was shown that the basal expression of overall sprr2 was almost undetectable. E2 alone significantly induced sprr2 expression, and the effect was partially abolished by progesterone (Fig. 6).

In the vaginas of the ovariectomized mice, only sprr $2 a$, GTase 3 and involucrin genes exhibited basal expression. The transcriptions of $s p r r 2 b, 2 d, 2 e, 2 f, 2 g, 2 h, 2 j$, $2 k$ and GTase 3 genes were evidently induced by E2 alone or the combination with E2 and progesterone (Fig. 5) as revealed by RT-PCR. Northern blot analysis revealed a low basal expression of the overall sprr 2 transcript and its stimulation by E2 alone or the combination of $\mathrm{E} 2$ and progesterone (Fig. 6).

\section{DISCUSSION}

In this paper, we investigated the expression patterns as well as the hormonal 


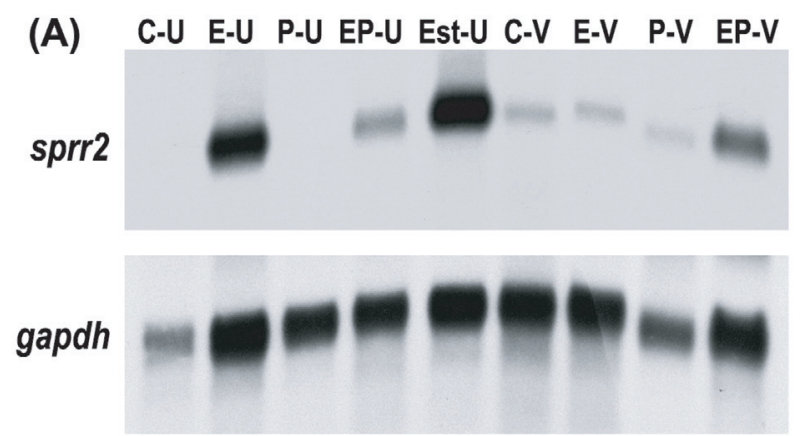

(B)

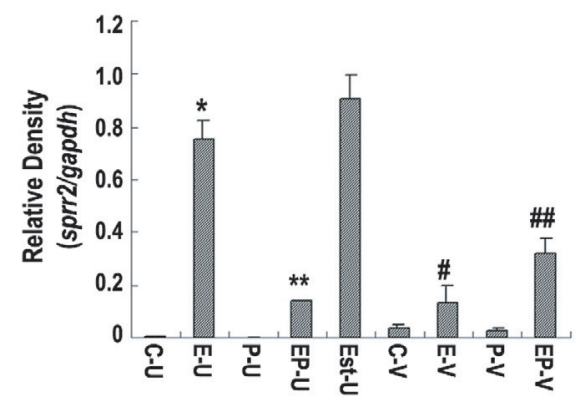

Figure 6. Northern blot analysis showing the regulation of overall sprr 2 mRNA by steroid hormones in the uterus and vagina of the ovariectomized mouse. The ovariectomized mice were treated with vehicle $(\mathrm{C})$, estradiol $(\mathrm{E})$, progesterone $(\mathrm{P})$ or the combination of estradiol and progesterone (EP) for 3 days, and RNA was extracted from the uteri (U) and vaginas (V). RNA from the estrous uterus (Est-U) was used as a positive control. A. Autoradiogram of a representing northern blot. B. Densitometric analysis of the autoradiograms. The relative amount of sprr2 was normalized by value of gapdh, and statistical analysis was performed by ANOVA according to the data from three independent experiments. * Compared with $\mathrm{C}-\mathrm{U}, P<0.05$; $* *$ compared with $\mathrm{E}-\mathrm{U}, P<0.05$; \# compared with $\mathrm{C}-\mathrm{V}, P<0.05$; \#\# compared with E-V, $P<0.05$.

regulation of sprr2 genes in the female mouse reproductive system.

The mechanisms involved in the regulation of sprr2 members are complicated. There are conserved TATA boxes in the core promoter of the known sprr2 members, and AP1 and OCT binding sites are present in these genes, except sprr $2 a$. However, many other conserved binding sites are not commonly dispersed, like Ets and kruppel binding sites [10]. The unique combination of these regulatory sites allows fine adjustment of each sprr2 gene expression in response to the same or different signals $[14,20]$. Unlike that in the skin, the transcriptional regulation of sprr2 members in the reproductive organs is under the control of cycling sex hormones as indicated in the present study. In the mouse, serum estrogen concentration reached a peak at the pro-estrous stage, started to drop at the estrous stage, decreased to the bottom level at the metestrous stage and increased again at the diestrous stage. Serum progesterone concentration is low at the proestrous and estrous stages, and high at the diestrous stage [21-23]. The genes up-regulated at 
the proestrous and estrous phases may be the direct or indirect targets of estrogen, and those induced at the metestrous and diestrous phases may be regulated by progesterone. In the present study, the expression of $s p r r 2 a, 2 b, 2 d$ and $2 e$ genes was induced in the proestrous and/or estrous uterus, and they were proved to be up-regulated by estradiol in the ovariectomized mice. Although the uterus, vagina and ovary are all the targets of steroid hormones, a given sprr2 member manifested different expression patterns in these tissues. For example, sprr2d was up-regulated in the uterus, while downregulated in the vagina at the estrous stage, and exhibited no cyclic change in the ovaries. The phenomenon indicated that some tissue-specific regulatory factors might intertwine with the steroid hormone signaling and complicate the transcriptional regulation of sprr 2 genes. The tissue-specific expression patterns of sprr2 genes also suggest that these molecules may participate in different events in various tissues. As a matter of fact, there is squamous epithelium in the vagina, in which CE is formed at the estrous stage (data no shown), while only a monolayer epithelium is found in the uterus throughout the estrous cycle.

Since the CE structure does not exist in the cycling uterus, the existence of sprr2 transcripts in the uterus may indicate their functions other than serving as precursors for CE formation. It was reported that the SPRR1 protein played a role in the nucleus and was associated with G0 entering of the cell cycle, and SPRR2 expression was reversely related to the proliferation state in the keratinocyte, partially due to the activation of p27, p21 and $\mathrm{p} 16^{\text {Ink4 } \alpha}$ [24-27]. Under the effects of cycling steroid hormones, uterine luminal and glandular epithelial cells have higher mitotic rates at the diestrous and proestrous stages, and undergo apoptosis at the estrous and metestrous stages [28].
Therefore, SPRR2 proteins might participate in the proliferation and apoptosis of uterine epithelial cells during the estrous cycle. Another possible role for uterine SPRR2 proteins may be anti-stress. Evidence has shown that SPRR2 proteins participate in the response to various stresses in many tissues without a stratified epithelium. In the biliary tract, the expression of SPRR2 members is highly induced under stress injury [29]. Similarly, SPRR1A and SPRR2A are strongly induced in cardiomyocytes responding to biomechanical/ischemic stress, and these proteins could protect cardiomyocytes against ischemic injury [30]. The SPRR2A protein was also reported to be highly induced in gastric mucosa upon Helicobacter pylori infection in the human stomach [31]. And SPRR genes are activated during IL-13 mediated immune response in the lung [32]. The female mouse accepts copulation only at the estrous stage, which will introduce pathogens to the vagina and uterus; meanwhile, the sperms may cause the changes of the physiological environment in the uterus. These are kinds of stresses for the mated females, and the upregulated SPRR2 expression at the estrous stage may be implicated in the stress response.

The expression of sprr2 in the mouse uterus also changed along with the gestational stages. In the mouse, on the 4th day postcoitus, the uterus undergoes the transformation towards a favorable molecular milieu for the implanting blastocysts. The down-regulated transcription of the sprr 2 gene from gestational day 3 on might be a prerequisite for "softening" of the uterine endometrium, which would be necessary for the adaptive change of the epithelium to support the blastocyst implantation and fetal growth hereafter. Likewise, the epithelial adhesion complex starts to dissociate from between 3.5 to 4.5 days of pregnancy with the cleavage of E-cadherin [33]. Interestingly, the sprr2 expression was highly 
induced around labor. It is known that the uterus undergoes shedding and involution during labor, and the uterine epithelial cells may bear much pressure and encounter tough condition. Here, the intensive inducement of sprr2 genes might imply the participation of their encoding proteins in the protective adjustment against the labor-associated stress, possibly by associating with cytoskeletons and other structural proteins to solidify the cellular structure.

Although SPRR2 proteins may participate in CE formation in the estrous vagina, the up-regulation of some sprr2 members in the metestrous vagina may indicate their additional roles. In the ovaries sprr $2 a, 2 b$, $2 d, 2 f, 2 j$ as well as involucrin and GTase 3 were also expressed in granula cells at a low level. Since granulosa cells support the follicular cavity, the SPRR2 proteins may also strengthen these cells against fluid pressure in the cavity. However, these proposals remain to be further determined.

In the present study, the expression patterns of sprr2 members in the uterus with a normal steroid-driven estrous cycle were not always in parallel with that in the ovariectomized mouse treated with estrogen and/or progesterone. For instance, transcription of sprr2f was estrogeninducible in the uteri of the ovariectomized mice, whereas a stable level was maintained in normal uteri throughout the estrous cycle. This indicated that the milieu in the uterus of the ovariectimized mouse was different from that in the normal one where the cellular events occur under the combined control of fluctuating estrogen, progesterone, $\mathrm{LH}, \mathrm{FSH}$ as well as some local factors including EGF and IGF, etc. [34-36].

In summary, the expression pattern of sprr 2 genes in the female mouse reproductive system during the estrous cycle and pregnancy was demonstrated. The proteins encoded by sprr 2 genes may participate in resisting the stress onto the uterine epithe- lia cells during mating and labor. Further study will be entailed to characterize their roles in the reproductive events. Among the genetic strategies, the knockout model does not seem ideal in that loss-of-function mutation of one sprr2 gene is very likely to be compensated for by other members. Applying the siRNA strategy to knockdown all sprr2 genes seems promising by using 21-nucleotides of lentivirus expressing homologues to transduce the embryo or mature uterus $[37,38]$.

\section{ACKNOWLEDGEMENTS}

The authors gratefully thank Prof. Linzhi Zhuang for her critical comments on the manuscript.

\section{REFERENCES}

[1] Tan YF, Li FX, Piao YS, Sun XY, Wang YL. Global gene profiling analysis of mouse uterus during the oestrous cycle. Reproduction 2003, 126: 171-182.

[2] Steinert PM. The complexity and redundancy of epithelial barrier function. J Cell Biol 2000, 151: F5-F8.

[3] Steven AC, Steinert PM. Protein composition of cornified cell envelopes of epidermal keratinocytes. J Cell Sci 1994, 107: 693-700.

[4] Tarcsa E, Candi E, Kartasova T, Idler WW, Marekov LN, Steinert PM. Structural and transglutaminase substrate properties of the small proline-rich 2 family of cornified cell envelope proteins. J Biol Chem 1998, 273: 23297-23303.

[5] Turksen K, Troy TC. Permeability barrier dysfunction in transgenic mice overexpressing claudin 6. Development 2002, 129: 17751784.

[6] Matsuki M, Yamashita F, Ishida-Yamamoto A, Yamada K, Kinoshita C, Fushiki S, Ueda E, Morishima Y, Tabata K, Yasuno H, Hashida M, Iizuka H, Ikawa M, Okabe M, Kondoh G, Kinoshita T, Takeda J, Yamanishi K. Defective stratum corneum and early neonatal death in mice lacking the gene for transglutaminase 1 (keratinocyte transglutaminase). Proc Natl Acad Sci USA 1998, 95: 1044-1049. 
[7] Djian P, Easley K, Green H. Targeted ablation of the murine involucrin gene. J Cell Biol 2000, 151: 381-388.

[8] Koch PJ, de Viragh PA, Scharer E, Bundman D, Longley MA, Bickenbach J, Kawachi Y, Suga Y, Zhou Z, Huber M, Hohl D, Kartasova T, Jarnik M, Steven AC, Roop DR. Lessons from loricrin-deficient mice: compensatory mechanisms maintaining skin barrier function in the absence of a major cornified envelope protein. J Cell Biol 2000, 151: $389-400$.

[9] Maatta A, DiColandrea T, Groot K, Watt FM. Gene targeting of envoplakin, a cytoskeletal linker protein and precursor of the epidermal cornified envelope. Mol Cell Biol 2001, 21: 7047-7053.

[10] Patel S, Kartasova T, Segre JA. Mouse Sprr locus: a tandem array of coordinately regulated genes. Mamm Genome 2003, 14: 140 148.

[11] Reddy SP, Konkin T, Wu R. Structure and organization of the genes encoding mouse small proline-rich proteins, mSPRR1A and 1B. Gene 1998, 224: 59-66.

[12] Gibbs S, Fijneman R, Wiegant J, van Kessel AG, van De Putte P, Backendorf C. Molecular characterization and evolution of the SPRR family of keratinocyte differentiation markers encoding small proline-rich proteins. Genomics 1993, 16: 630-637.

[13] Song HJ, Poy G, Darwiche N, Lichti U, Kuroki T, Steinert PM, Kartasova T. Mouse Sprr2 genes: a clustered family of genes showing differential expression in epithelial tissues. Genomics 1999, 55: 28-42.

[14] Cabral A, Voskamp P, Cleton-Jansen AM, South A, Nizetic D, Backendorf C. Structural organization and regulation of the small proline-rich family of cornified envelope precursors suggest a role in adaptive barrier function. J Biol Chem 2001, 276: 1923119237.

[15] Jetten AM, De Luca LM, Nelson K, Schroeder W, Burlingame S, Fujimoto W. Regulation of cornifin alpha expression in the vaginal and uterine epithelium by estrogen and retinoic acid. Mol Cell Endocrinol 1996, 123: 7-15.

[16] Nelson JF, Felicio LS, Randall PK, Sims C, Finch CE. A longitudinal study of estrous cyclicity in aging C57BL/6J mice: I. Cycle frequency, length and vaginal cytology. Biol Reprod 1982, 27: 327-339.
[17] Paria BC, Ma W, Tan J, Raja S, Das SK, Dey SK, Hogan BL. Cellular and molecular responses of the uterus to embryo implantation can be elicited by locally applied growth factors. Proc Natl Acad Sci USA 2001, 98: 1047-1052.

[18] Kurita T, Lee KJ, Cooke PS, Lydon JP, Cunha GR. Paracrine regulation of epithelial progesterone receptor and lactoferrin by progesterone in the mouse uterus. Biol Reprod 2000, 62: 831-838.

[19] Qin L, Wang YL, Bai SX, Ji SH, Qiu W Tang S, Piao YS. Temporal and spatial expression of integrins and their extracellular matrix ligands at the maternal-fetal interface in the rhesus monkey during pregnancy. Biol Reprod 2003, 69: 563-571.

[20] Sark MW, Fischer DF, de Meijer E, van De Putte P, Backendorf C. AP-1 and ets transcription factors regulate the expression of the human SPRR1A keratinocyte terminal differentiation marker. J Biol Chem 1998, 273: 24683-24692.

[21] Barkley MS, Lasley BL, Thompson MA, Shackleton CH. Equol: a contributor to enigmatic immunoassay measurements of estrogen. Steroids 1985, 46: 587-608.

[22] Bergman MD, Schachter BS, Karelus K, Combatsiaris EP, Garcia T, Nelson JF. Upregulation of the uterine estrogen receptor and its messenger ribonucleic acid during the mouse estrous cycle: the role of estradiol. Endocrinology 1992, 130: 1923-1930.

[23] Walmer DK, Wrona MA, Hughes CL, Nelson KG. Lactoferrin expression in the mouse reproductive tract during the natural estrous cycle: correlation with circulating estradiol and progesterone. Endocrinology 1992, 131: 1458-1466.

[24] Harvat BL, Wang A, Seth P, Jetten AM. Up-regulation of p27Kip1, p21WAF1/Cip1 and p16Ink4a is associated with, but not sufficient for, induction of squamous differentiation. J Cell Sci 1998, 111: 1185-1196.

[25] Lohman FP, Medema JK, Gibbs S, Ponec M, van De Putte P, Backendorf C. Expression of the SPRR cornification genes is differentially affected by carcinogenic transformation. Exp Cell Res 1997, 231: 141-148.

[26] Tesfaigzi J, Carlson DM. Expression, regulation, and function of the SPR family of proteins. A review. Cell Biochem Biophys 1999, 30: 243-265. 
[27] Tesfaigzi Y, Wright PS, Belinsky SA. SPRR1B overexpression enhances entry of cells into the G0 phase of the cell cycle. Am J Physiol Lung Cell Mol Physiol 2003, 285: L889-L898.

[28] Sato T, Fukazawa Y, Kojima H, Enari M, Iguchi T, Ohta Y. Apoptotic cell death during the estrous cycle in the rat uterus and vagina. Anat Rec 1997, 248: 76-83.

[29] Nozaki I, Lunz JG, 3rd, Specht S, Stolz DB, Taguchi K, Subbotin VM, Murase N, Demetris AJ. Small proline-rich proteins 2 are noncoordinately upregulated by IL-6/STAT3 signaling after bile duct ligation. Lab Invest 2005, 85: 109-123.

[30] Pradervand S, Yasukawa H, Mulle OG, Kjekshus H, Nakamura T, St Amand TR, Yajima T, Matsumura K, Duplain H, Iwatate M, Woodard S, Pedrazzini T, Ross J, Firsov D, Rossier BC, Hoshijima M, Chien KR. Small proline-rich protein $1 \mathrm{~A}$ is a gp130 pathway- and stress-inducible cardioprotective protein. Embo J 2004, 23: 4517-4525.

[31] Mueller A, O’Rourke J, Grimm J, Guillemin K, Dixon MF, Lee A, Falkow S. Distinct gene expression profiles characterize the histopathological stages of disease in Helicobacter-induced mucosa-associated lymphoid tissue lymphoma. Proc Natl Acad Sci USA 2003, 100: 1292-1297.
[32] Finkelman FD, Yang M, Perkins C, Schleifer K, Sproles A, Santeliz J, Bernstein JA, Rothenberg ME, Morris SC, Wills-Karp M. Suppressive effect of IL-4 on IL-13-induced genes in mouse lung. J Immunol 2005, 174: 4630-4638.

[33] Potter SW, Gaza G, Morris JE. Estradiol induces E-cadherin degradation in mouse uterine epithelium during the estrous cycle and early pregnancy. J Cell Physiol 1996, 169: $1-14$.

[34] Hull KL, Harvey S. Growth hormone: roles in female reproduction. J Endocrinol 2001, 168: 1-23.

[35] Leung PC, Steele GL. Intracellular signaling in the gonads. Endocr Rev 1992, 13: 476498.

[36] Wang HS, Chard T. IGFs and IGF-binding proteins in the regulation of human ovarian and endometrial function. J Endocrinol 1999, 161: 1-13.

[37] Kunath T, Gish G, Lickert H, Jones N, Pawson T, Rossant J. Transgenic RNA interference in ES cell-derived embryos recapitulates a genetic null phenotype. Nat Biotechnol 2003, 21: 559-561.

[38] Tiscornia G, Singer O, Ikawa M, Verma IM. A general method for gene knockdown in mice by using lentiviral vectors expressing small interfering RNA. Proc Natl Acad Sci USA 2003, 100: 1844-1848. 